\title{
A Atuação da Psicologia na Proteção Social Básica
}

\author{
Byanca Eugênia Duarte Silva ${ }^{1}$; Henry Witchael Dantas Moreira ${ }^{2}$;Andreia Braga de Oliveira ${ }^{3}$; \\ Maria Auxiliadora Lobo Silva ${ }^{4}$ Ana Roberta Duarte Piancó ${ }^{5}$
}

Resumo: A proteção social básica têm seus princípios pautados na Assistência Social e, consequentemente, assegurados pela LOAS (Lei Orgânica de Assistência Social) de 1993, que dispõe sobre essa assistência como política pública onde as necessidades básicas dos indivíduos devem ser atendidas e respeitadas. Nesse contexto, o CRAS (Centro de Referência de Assistência Social) aparece como principal porta de acesso das famílias em situações de vulnerabilidade à rede de proteção social, ofertando a prevenção e o cuidado aos sujeitos sociais fragilizados economicamente e afetivamente. Este artigo que objetiva compreender as possíveis contribuições da atuação da Psicologia na Proteção Social Básica, justifica-se pela possibilidade de investigar o trabalho do profissional de Psicologia na Assistência Social de modo a conhecer suas necessidades e ofertar a socialização e a convivência dos sujeitos vulneráveis, visando o bom desenvolvimento da função do psicólogo e os benefícios para a população. A metodologia utilizada consiste em pesquisa qualitativa mediante referencial bibliográfico realizado em fontes de buscas como o Scielo e Google acadêmico, além de livros e revistas e demais fontes próprias. Como resultado, espera-se através desta pesquisa ofertar perspectivas para que o trabalho do Psicólogo nos Centros de Referências de Assistência Social contemplem as necessidades dos usuários, fortalecendo os vínculos familiares e resgatando valores e dignidades da pessoa humana. Além disso, acredita-se que este trabalho pode subsidiar novos estudiosos, acadêmicos de cursos referentes a área e demais seres sociais que tenham interesse pela temática em questão.

Palavras-chave: CRAS. Política de Assistência Social. Proteção Social Básica. Psicologia.

\section{The Performance of Psychology in Basic Social Protection}

\begin{abstract}
Basic social protection has its principles based on Social Assistance and, consequently, guaranteed by LOAS (Organic Law of Social Assistance) of 1993, which provides for this assistance as a public policy where the basic needs of individuals must be met and respected. In this context, the CRAS (Social Assistance Reference Center) appears as the main access door for families in situations of vulnerability to the social protection network, offering prevention and care to socially and economically fragile individuals. This article, which aims to understand the possible contributions of Psychology in Basic Social Protection, is justified by the possibility of investigating the work of the Psychology professional in Social Assistance in order to know their needs and offer the socialization and the coexistence of vulnerable individuals, aiming at the good development of the psychologist's function and the benefits for the population. The methodology used consists of qualitative research using a bibliographic reference made in search sources such as Scielo and Google academic, as well as books and magazines and other sources. As a result, it is expected through this research to offer perspectives so that the work of the Psychologist in the Social Assistance Referral Centers contemplate the needs of the users, strengthening the family ties and rescuing values and dignities of

\footnotetext{
${ }^{1}$ Psicóloga pela Faculdade Santa Maria. Especialista em Docência do Ensino Superior e em Psicopedagogia Clínica e Institucional. Especializanda em Terapia Cognitivo-comportamental. Professional Life \& Coach pelo instituto BBC.

${ }^{2}$ Fisioterapeuta pela Universidade Federal da Paraíba. Especialista em cardiorrespiratória. Fisioterapeuta do Hospital Regional de Cajazeiras e do Município de Santa Helena - PB. Secretário municipal de saúde de Cajazeiras na gestão 2013 a 2016.

${ }^{3}$ Assistente Social. Graduada em Direito.

${ }^{4}$ Mestranda em Educação pela Unissulivan Inc. Contato: lobosilvamestrado@ outlook.com;

${ }^{5}$ Mestrado em Geografia pela Universidade Federal de Pernambuco, Brasil. Professor Titular da Universidade Regional do Cariri , Brasil. Contato: robertapianco@hotmail.com
} 
the human person. In addition, it is believed that this work can subsidize new scholars, academics of courses related to the area and other social beings who are interested in the subject in question.

Keywords: CRAS. Social Assistance Policy. Basic Social Protection. Psychology.

\section{Introdução}

O presente artigo tem como objeto de estudo a atuação da Psicologia nas Políticas Públicas de Assistência Social. A escolha do tema se deu em virtude da necessidade de se pesquisar e debater sobre a percepção dos sujeitos que vivem em condições de vulnerabilidade acerca da atuação da Psicologia. Considera-se que a forma como os sujeitos percebem a Psicologia, e a atuação da Psicologia no âmbito das Políticas Públicas de Assistência Social repercute diretamente na forma como estes sujeitos acessam os serviços disponibilizados por meio do Centro de Referência da Assistência Social, o que faz com que tal percepção se constitua como uma variável importante que influencia na atuação da Psicologia no CRAS (JACÓ-VILELA, 2012).

É importante que a percepção social dos usuários sobre o trabalho do (a) psicólogo (a) no CRAS mediante sua atuação nesse Centro de Referência de Assistência Social, seja considerada e analisada. Assim sendo, espera-se que esta pesquisa contribua para uma melhor análise da atuação do psicólogo com os indivíduos que vivem em condição de vulnerabilidade social, influenciando de maneira positiva na compreensão dos seus questionamentos e dúvidas perante a sua realidade (LUCCI, 2015).

Este trabalho demonstra sua relevância social e acadêmica ao objetivar melhoras nas condições de vida da população, por meio do fortalecimento dos vínculos familiares e comunitários, enfrentando as sequelas da condição de pobreza. Essa realidade permite uma nova holística do centro acadêmico para com os problemas sociais preponderantes.

Assim, a pesquisa tem como parâmetros para análises os estudos de Brasil (2016), Crus (2006), Lucci (2015), Zavaschi (2009) e Wachholz e Panceri (2015), bem como os marcos legais da Política Pública de Assistência Social e os referenciamentos técnicos do Conselho Federal de Psicologia - CFP, os quais discorrem sobre como deve se dar a atuação dos profissionais de Psicologia no âmbito das Políticas Públicas de Assistência Social. Seu percurso 
metodológico resulta de uma pesquisa bibliográfica de cunho qualitativo, e tem como percursor o desejo de contribuição para a atuação da psicologia na proteção social básica.

\section{Política Pública de Assistência Social no CRAS}

Para se compreender a importância e complexidade do trabalho do psicólogo em instituições de apoio a pessoas vulneráveis, faz-se necessário fazer uma alusão a Assistência Social, como política pública de proteção social, a qual se configura como algo recente e inovador, pois somente a partir de 1988, esta foi assegurada pela Constituição Federal do país. A partir de então, a Assistência Social passou a integrar o Sistema de Seguridade Social, como política pública não contributiva, pautada pela universalidade da cobertura e do atendimento. Esse fato permitiu uma atividade em conjunto entre vários profissionais, entre eles, o psicólogo (PIVETA; MANSANO, 2014).

A Assistência Social passou a ser um dever do Estado e um direito de todos os cidadãos que necessite do tipo de atendimento oferecido nos estabelecimentos apropriados. A Lei Orgânica de Assistência Social - Lei n.8.742, de 07 de Dezembro de 1993, dispõe sobre a organização da Assistência Social e outras disposições. Tal lei permitiu que a Assistência Social, fosse considerada um dever do Estado e um direito inquestionável de cidadania, sem a necessidade de contribuição prévia que garantisse nenhum acordo.

Nessa perspectiva, de acordo com o artigo $1^{\circ}$ da LOAS (Lei Orgânica de Assistência Social), a mesma é compreendida como Política de Seguridade Social não contributiva, que provê os mínimos sociais, realizada através de um conjunto integrado de ações de iniciativa pública e da sociedade, para garantir o atendimento às necessidades básicas. A LOAS dispõe de 42 artigos sobre a organização da Assistência Social, tendo como principais temas tratados: Princípios e diretrizes; Competências das esferas de governo; Conceito de benefícios, serviços, programas e projetos; Instituição e competências do Conselho Nacional de Assistência Social; Competências do órgão nacional gestor da PNA; Financiamento da política; Forma de organização e gestão das ações e, caráter e composição das instâncias deliberativas (PIVETA; MANSANO, 2014).

Desse modo, na LOAS a concepção de assistência social parte do indivíduo para o indivíduo, visando assegurar benefícios continuados e eventuais sempre acolhendo os sujeitos 
vulneráveis de forma unânime. Destacam-se, também, programas, projetos e serviços sócio assistenciais para enfrentar as condições de vulnerabilidades que fragilizam a resistência do cidadão e da família ao processo de exclusão sociocultural em todos os seus âmbitos.

Em busca do cumprimento do que propõe a LOAS, foi definido um sistema de padronização e regulamento dos projetos, programas e ações da assistência, o Sistema Único de Assistência Social, de modo a contemplar todos os vieses das propostas fundadas.

Significa que a pobreza hoje é vista como resultado da ação do homem, do sistema, e não de uma determinação divina, ainda que haja circunstancias imprevisíveis que possam causar situações de pobreza. É fruto do modelo econômico, político e social adotado no país, gerador de desigualdade social e da exclusão social (PEREIRA, 2006, p. 62).

Tal definição favorece a compreensão de que as vítimas de exclusão social proveniente da pobreza passaram a ser incluída num conceito abrangente de resultado das ações do sistema político que rege as leis, a distribuição de renda e a permanência humana num ciclo vicioso de geração de renda para os mais favorecidos e abandono total de um grupo desfavorecido.

Em uma perspectiva diferenciada, Wachholz e Panceri (2015) observam de maneira totalitária a importância da Assistência Social a nível geral:

O Sistema Único de Assistência Social (SUAS), cujo modelo de gestão é descentralizado e participativo, constitui-se na regulação e organização em todo território nacional dos serviços, programas, projetos e benefícios sócio assistenciais, de caráter continuado ou eventual, executados e providos por pessoas jurídicas de direito público sob critério universal e lógica de ação em rede hierarquizada e em articulação com iniciativas da sociedade civil (WACHHOLZ; PANCERI, 2015, p. 4).

A diferença na forma de agir, é que engloba um maior número de serviços, onde a ação ultrapassa algumas barreiras e atinge o público alvo de maneira unânime. Ao organizar e regular os serviços sócio assistenciais em todo o país, esse sistema único assume o compromisso com a população na execução de projetos ou qualquer tipo de serviço mediante controle de pessoas jurídicas.

Assim, o SUAS age sob definição e organização dos elementos imprescindíveis à execução da política pública de assistência social, já que estes são essenciais às ações jurídicas que controlam todo o processo, possibilitando a normatização dos padrões nos serviços, qualidade absoluta no atendimento as individualidades dos usuários, indicadores de avaliação 
e resultado de forma transparente, nomenclatura dos serviços no intuito de tornar pública a ação desenvolvida e denominação da rede prestadora de serviços sócios assistenciais.

Crus (2006) destaca que o SUAS foi à principal deliberação da IV Conferência Nacional de Assistência Social, realizada em 2003 em Brasília, e se inscreve no esforço de viabilização de um projeto de desenvolvimento nacional, que pleiteia a universalização dos direitos à Seguridade Social e da proteção social pública com a composição da política pública de assistência social em nível nacional.

\begin{abstract}
A organização na perspectiva de um sistema tem como objetivo romper com uma forte tendência de oferta de serviços, programas, projetos e benefícios sócios assistenciais segmentados e desarticulados, sem definição de referencias e contra referências, fluxos e procedimentos de recepção e intervenção social, gerando superposição e paralelismo de serviços. (CRUS, 2006, p. 81).
\end{abstract}

Observa-se a busca por uma organização através de um sistema que vise controlar e acompanhar todas as despesas, o número de pessoas atendidas, as ofertas estabelecidas nos projetos e a maneira como se dá a prestação de serviço. Esse esforço pauta-se na desarticulação de determinados tipos de serviços prestados sem referências que os comprove.

Busca-se, portanto, estabelecer através desse sistema as responsabilidades das esferas de governo (federal, estadual e municipal) assegurando-lhes competências e compromissos com o que for firmado em cada acordo previsto. Diante da observação de casos específicos pautados em pluralidades que os individualiza, chegou-se a definição de níveis de complexidade do sistema, a saber: Proteção Social Básica (PSB) e Proteção Social Especial (PSE) de média e alta complexidade. Toda a ação do sistema considera alguns pontos de acordo com as diferenças contextuais do ambiente onde se dá a atuação. Desse modo, considera-se a referência no território, considerando as especificidades das regiões e portes de municípios e com centralidade na família. Portanto, é uma forma de operacionalização da Lei Orgânica da Assistência Social (LOAS), que viabiliza o sistema descentralizado e participativo e a sua regulação em todo o território nacional (PIVETA; MANSANO, 2014).

Agindo de modo a prevenir situações de risco por meio do desenvolvimento de potencialidades e aquisições, e o fortalecimento de vínculos familiares e comunitários, a proteção social básica pauta-se na prevenção e cuidado com os sujeitos sociais, garantindo bem estar e qualidade de vida às famílias e a sociedade de um modo geral. De acordo com o 
Ministério do Desenvolvimento Social e Combate à Fome - MDS, os CRAS podem ser definidos como:

\begin{abstract}
Uma unidade pública estatal descentralizada da política de assistência social, responsável pela organização e oferta de serviços da proteção social básica do Sistema Único de Assistência Social (SUAS) nas áreas de vulnerabilidade e risco social dos municípios e DF. Dada sua capilaridade nos territórios, se caracteriza como a principal porta de entrada do SUAS, ou seja, é uma unidade que possibilita o acesso de um grande número de famílias à rede de proteção social de assistência social (BRASIL, 2009b, p. 9).
\end{abstract}

Destina-se, portanto, à população que vive em situação de vulnerabilidade social decorrente da pobreza ou fragilização de vínculos afetivos - relacionais e de pertencimento social como discriminações etárias, étnicas, de gênero ou por deficiências, dentre outras. Essa observação considera a totalidade das diferenças sociais e características que distingue os grupos em seu meio, dando-lhes status de ser humano único e incomparável.

Diante dessa compreensão, Wachholz e Panceri (2015) traz algumas considerações acerca desse tipo de assistência social ao afirmar que esta:

\begin{abstract}
Prevê o desenvolvimento de serviços, programas e projetos locais de acolhimento, convivência e socialização de famílias e de indivíduos, conforme identificação da situação de vulnerabilidade apresentada. Deverão incluir as pessoas com deficiência e ser organizados em rede, de modo a inseri-las nas diversas ações ofertadas. Os benefícios, tanto de prestação continuada como os eventuais, compõem a proteção social básica, dada à natureza de sua realização. São eles: Programa de Atenção Integral às Famílias - PAIF; Programas de inclusão produtiva e projetos de enfrentamento da pobreza; Centro de Convivências para Idosos; Serviços para crianças de 0 a 6 anos, que visem o fortalecimento do vínculo familiar, com ações que favoreçam a socialização do brinquedo e a defesa dos direitos da criança; Serviços socioeducativos para crianças e adolescentes na faixa de 6 a 14 anos, visando a sua proteção, socialização e o fortalecimento dos vínculos familiares e comunitários; Programas de incentivo ao protagonismo juvenil, com fortalecimento dos vínculos familiares e comunitários; Centros de Informação e Educação para o Trabalho para jovens e adultos. (WACHHOLZ; PANCERI, 2015, p. 6).
\end{abstract}

Observa-se um acolhimento centrado especificamente na família, desde a infância até a velhice, ou seja, busca-se traçar organizar e oferecer serviços de qualidade com foco no melhoramento das relações interpessoais. Assim, o CRAS - Centro de Referência de Assistência Social pode gerir todos esses serviços, já que este é uma unidade pública estatal, que atua com famílias e indivíduos em seu contexto comunitário mediante vulnerabilidades referentes a problemas sociais diversos, visando assim, à orientação e o fortalecimento do convívio sócio familiar, no intuito de melhorar a relação parental e social em geral. 
Em contrapartida, aparece outra forma de assistência social considerando aspectos mais acentuados de problemas sociais envolvendo a família. Desse modo, Wachholz e Panceri (2015) asseguram que:

\begin{abstract}
A Proteção Social Especial (PSE) do Sistema Único de Assistência Social é destinada a famílias e indivíduos que se encontram em situação de risco pessoal e social, por ocorrência de abandono, maus tratos físicos e/ou psíquicos, abuso sexual, uso de substâncias psicoativas, cumprimento de medidas socioeducativas, situação de rua, situação de trabalho infantil, entre outras situações de violação dos direitos. Os serviços de proteção social especial têm estreita interface com o sistema de garantia de direito, exigindo, muitas vezes, uma gestão mais complexa e compartilhada com o Poder Judiciário, o Ministério Público e com outros órgãos e ações do Executivo. (WACHHOLZ; PANCERI, 2015, p. 6).
\end{abstract}

Considerando os riscos pessoais e sociais a que estão expostos as vitimas, a Proteção Social Especial parte do pressuposto de que o atendimento envolvendo os profissionais especializados no cuidado com os problemas humanos, inclusive o psicólogo, precisam estar atentos ao grau de vulnerabilidade de cada fato e cada caso em especial. Essa maneira de agir considera vários tipos de problemas que afetam cotidianamente as famílias em situação de violação de direitos. Desse modo, a proteção social especial divide-se em: média e alta.

São considerados serviços de média complexidade aqueles que oferecem atendimento às famílias e indivíduos com seus direitos violados, mas cujos vínculos familiares e comunitários permanecem sem rompimentos. Wachholz e Panceri (2015) a entendem afirmando que: A proteção social de média complexidade é organizada nos Centros de Referência
Especializados de Assistência Social (CREAS), que são unidades públicas estatais.
Neles, são ofertados serviços socioassitenciais que requerem acompanhamento
individual e maior flexibilidade nas soluções protetivas. Da mesma forma, requerem
maior estruturação técnico-operacional e atenção especializada e mais
individualizada, comportam encaminhamentos monitorados e sistemáticos, apoios e
processos que assegurem qualidade na atenção protetiva e efetividade na reinserção
almejada. Estes serviços incluem o Serviço de Orientação e Apoio Sócio-familiar;
Plantão Social; Abordagem de Rua; Cuidado no domicílio; Serviço de Habilitação e
Reabilitação de pessoas com deficiência e Medidas socioeducativas em meio aberto.
(WACHHOLZ; PANCERI, 2015, p. 7).

Desse modo, o questionamento sobre média complexidade, traz à tona a possibilidade de trabalhar com um grupo de sujeitos vulneráveis, porém capazes de se relacionar ativamente em seu cotidiano com o grupo no qual está inserido. O afastamento é considerado desnecessário 
em sua totalidade, uma vez que os necessitados de atendimento não representam perigo claro aos demais ou não estão expostos a condições extremas de maus tratos.

Diante da explanação sobre proteção social básica e especial, sendo que a última pode ser de média e alta complexidade, Wachholz e Panceri (2015) entendem que os serviços de proteção social especial de alta complexidade são aqueles que garantem proteção integral ao acolhido mediante oferecimento de moradia, alimentação, higienização e trabalho protegido para famílias e indivíduos que se encontram sem referência e/ou em situação de ameaça, necessitando ser retirado do convívio familiar e/ou comunitário, ou seja, é uma maneira eficaz de proteger e garantir a cidadania e a vida.

\begin{abstract}
A alta complexidade compõe o Atendimento Integral Institucional; Casa Lar; República; Casa de Passagem; Albergue; Família Substituta; Família Acolhedora; Medidas Socioeducativas restritivas e privativas da liberdade, previstas no Estatuto da Criança e do Adolescente (Semi-liberdade, internação provisória e sentenciada) e Trabalho Protegido. Cabe definir que o SUAS deverá ter ações de proteção básica na totalidade dos municípios brasileiros. Já, as ações de proteção social especial, deverão ser executadas por municípios de médio e grande porte (WACHHOLZ; PANCERI, 2015, p. 7).
\end{abstract}

Desse modo, a complexidade envolve um número maior de ações e assistência, englobando um cuidado integral de um indivíduo ou grupo vulnerável. A partir da concepção de que é preciso oferecer condições mínimas de desenvolvimento aos sujeitos, a alta complexidade integra ações e atua em rede, já que tratar um problema social requer que este seja analisado, compreendido e assistido de acordo com as dimensões que o caracterizam e os distinguem momentaneamente.

\title{
A Psicologia na Proteção Social Básica
}

Na década de 1960, surge uma nova Psicologia voltada para os problemas sociais e as necessidades da população menos favorecida. Essa nova forma de atuação ficou conhecida como Psicologia Social, a qual segundo Song (2010) se iniciou com a participação dos Psicólogos e professores Sílvia Lane e Alberto Andery em um bairro periférico da cidade de São Paulo. Na ocasião, professores e alunos realizaram pesquisa e estágio se contrapondo à Psicologia a-histórica e descontextualizada da realidade social do país. 
Assim, a Psicologia na comunidade pretende aproximar-se das classes populares e da realidade dos indivíduos que nela habita, ajudando-as na conscientização de sua identidade psicossocial e suas condições de superação. Desse modo, os profissionais passaram a atuar fora dos consultórios, indo de encontro à população.

No Brasil, a carreira de psicólogo comunitário vai se iniciar em 1970, com a implantação dessa disciplina na formação acadêmica. Demonstrando a importância de um trabalho integral entre profissionais e comunidade, Filho (2005) salienta que:

\footnotetext{
a psicologia social comunitária trabalha para o fortalecimento da sociedade civil, para que sujeitos organizem-se coletivamente, desenvolvam uma clara consciência de seus direitos e deveres como cidadãos, assumindo uma posição política explícita e voltada à garantia da cidadania àqueles que têm sido submetidos à opressão da classe dominante (FILHO, 2005, p.127).
}

Para Filho (2005), de um modo geral, a Psicologia Social visa acrescentar às análises micro estruturais dos processos psicossociais os elementos emocionais, como mediações fundamentais presentes no processo de construção da identidade e da consciência social. Desse modo, o indivíduo e seus problemas são acompanhados pela assistência psicológica mediante acompanhamento e cuidados básicos.

Nessa perspectiva, compreender a importância social do Centro de Referência de Assistência Social (CRAS) significa observar que os municípios detentores dessas unidades exercem uma prestação de serviço acolhedora, onde o ser humano vulnerável é o principal ator do processo que busca a recuperação deste e do seu grupo familiar.

Analisando as diversas formas de assistência social, o psicólogo aparece como membro atuante enquanto trabalhador da assistência. Wachholz e Panceri (2015) observam a importância desse profissional na prestação de serviços, afirmando que o Sistema Único de Assistência Social, busca uma gestão organizada mediante a participação de vários profissionais, já que “Além de firmar a participação de técnicos de áreas bem distintas, também inclui o psicólogo como um dos técnicos de fundamental importância na execução dos projetos, programas e ações descritos pelo SUAS" (WACHHOLZ; PANCERI, 2015, p. 8). Sua contribuição vai além do simples fato de buscar entender a subjetividade do outro, considera, sobretudo, a essência humana.

Mediante as considerações que sustentam sua formação, o psicólogo pode participar de todas as ações do CRAS, articulando a sua atuação a um plano de trabalho elaborado em conjunto com a equipe interdisciplinar que atua em cada centro de apoio. A partir do 
conhecimento do território, ou seja, contexto habitado pelos usuários e das famílias que nele vivem, as ofertas de serviços devem privilegiar a fragilidade dos envolvidos, os riscos a que estão expostos, seus pontos fracos e fortes, as necessidades individuais e coletiva e, principalmente, as melhores condições de ajudá-los na superação de seus problemas.

A atuação psicológica no trabalho com Proteção Social Básica requer um apoio peculiar de bases bibliográficas que fundamentem a assistência e a compreensão dos problemas de cada paciente mediante suas necessidades. Compreendendo que existe uma dimensão subjetiva dos fenômenos sociais. Nesse contexto, a Cartilha do CRAS (2016) destaca que:

CRAS é a referência para o desenvolvimento de todos os serviços socioassistenciais de proteção social básica do SUAS. Isso significa que os serviços devem estar sempre em contato com o CRAS, no respectivo território de abrangência, tomando-o como ponto de referência. Estes serviços, de caráter preventivo, protetivo e proativo, podem ser ofertados diretamente no CRAS, desde que haja espaço físico e equipe, sem prejuízo das atividades do PAIF, que deve ser ofertado exclusivamente pelo CRAS [...]. (BRASIL- MDS, 2016, p. 7).

A compreensão das singularidades de cada sujeito enquanto pessoa passa a ser avaliada pela Psicologia de forma dinâmica, onde os indivíduos são considerados plurais em suas ideias, anseios, medos e perspectivas. Pensar num ser único significa olhá-lo de diferentes ângulos, onde a diversidade aparece como mediadora de uma análise pautada no bom senso e respeito aquilo que cada um é de verdade.

A interação social, as diversas manifestações entre os seres humanos e o convívio diário, é referencial para análise das personalidades, tendo em vista a importância dos comportamentos individuais e coletivos dos sujeitos sociais. Cada indivíduo necessitado de Proteção Social Básica requer uma compreensão dos seus problemas sob a ótica de superação das suas dificuldades (JACÓ-VILELA, 2012). Observa-se que o compromisso fundamentado pela responsabilidade social da profissão podem se revelar em uma intervenção crítica por parte do próprio profissional que leva a uma ação transformadora da situação do usuário, particularmente nos estabelecimentos de medida protetiva, em que uma das tarefas da Psicologia é fazer-se presente agindo e mediando os interesses dos envolvidos quando há iminente ameaça à dignidade humana, seja esta de forma física ou emocional.

A atuação do psicólogo deve ser orientada pelas várias formas de intervenção próprias da Psicologia no cotidiano da instituição, ou seja, o profissional precisa ter conhecimento absoluto do problema que lhe foi confiado, para que, no entanto, aja de acordo com as 
especificidades dos sujeitos (JACÓ-VILELA, 2012). Sejam no CRAS ou demais instituições de apoio, a atenção à família ajudará na recuperação do indivíduo em condições sociais de vulnerabilidade e aceitação por parte dos parentes sem julgamento ou rejeição. Considerando a importância da reunião entre familiares, Melman (2001) Considera que esses encontros estimulam as famílias a assumirem responsabilidades com seus parentes.

\footnotetext{
Ouvir o relato de outra pessoa pressupõe uma disponibilidade para acolher o sofrimento e a angústia do outro, assim como perceber pontos de contato e vivencias semelhantes às suas próprias narrativas. $\mathrm{O}$ processo de identificação facilita aos participantes ver no outro o reflexo de sua própria realidade, aliviando a sensação de isolamento e solidão, muito comum entre eles, além de contribuir para a própria construção do grupo como espaço de referência e de experimentação. (MELMAN, 2001, p.95).
}

A análise da condição social dos envolvidos torna-se importante devido à fragilidade que oferece a um grupo. Os ambientes de recuperação, em especial o CRAS, são espaços acolhedores, organizativos e desafiadores promovendo estímulos saudáveis para a superação dos problemas que prejudicam o desenvolvimento dos usuários.

Como afirma Lane (2001), cabe a Psicologia recuperar o indivíduo na interseção de sua história com a história de sua sociedade, uma vez que é somente este conhecimento que permite compreender o homem como produtor de sua história. Assim, a participação social é condição básica à cidadania e condição essencial à pessoa humana.

\section{A Influência do Processo Histórico-Cultural na Formação Psicossocial do Sujeito}

Buscar-se-á suporte teórico, para a realização da presente pesquisa, na perspectiva Histórico-cultural de Vigotski. A mesma pode ser entendida como sendo o resultado de um longo período de estudos e descobertas sobre o ser humano em toda a sua dimensão e desenvolvimento. O teórico em questão busca compreender a importância das relações sociais para o desenvolvimento do sujeito. Esse foi um dos grandes desafios ao seu trabalho como pesquisador da individualidade do sujeito.

De acordo com Lucci (2015), os interesses de Vygotski pela psicologia originam-se na preocupação com a gênese da cultura, ou seja, na busca pelo entendimento de casos específicos de acordo com o contexto em que está inserido. Por entender que o homem é o 
construtor da cultura, ele se contrapõe à psicologia clássica que, segundo sua visão, não respondia adequadamente sobre os processos de individuação e os mecanismos psicológicos dos indivíduos. Desse modo elaborou sua teoria considerando a origem e natureza social dos processos psicológicos dos seres humanos.

De acordo com as Referências Técnicas para atuação do (a) psicólogo (a) no CRAS/SUAS (BRASIL, 2007, p. 17)), “a capacidade de enfrentamento das situações da vida é afetada pelas experiências, condições de vida e significados construídos ao longo do processo de desenvolvimento". Por isso, é importante observar a história de vida de cada indivíduo acolhido.

Ao tratar sobre a interação entre os homens, comunicação entre eles e a própria possibilidade da sua consciência se adaptar e refletir sobre si mesmo e sua prática, Vigotski (1995) assegura que:

(...) as relações entre as pessoas podem ser de dois tipos: mediadas e imediatas. São imediatas aquelas que se baseiam em formas instintivas do movimento e da ação expressiva (automática e instintiva) (...) Em um nível superior de desenvolvimento aparecem, sem dúvida, relações mediatizadas entre as pessoas, cuja característica essencial é o signo, e que com sua ajuda se estabelece essa comunicação. Desse modo, as formas superior de comunicação-mediatizada pelo signo- cresce a partir das formas naturais de comunicação imediata: não obstante, elas se diferenciam, essencialmente, entre si. (VIGOTSKI, 1995, p. 159).

A forma de pensar de Vigotski considera que os signos são instrumentos psicológicos produzidos culturalmente e socialmente pelos sujeitos nas relações cotidianas que se dão no tempo e no espaço. O homem é objetivado e subjetivado mediante suas atividades na sociedade, condição que o torna participante ativo do meio e da realidade humanizada que relaciona cada vez mais sujeito e ambiente de vivência.

De acordo com Lucci (2015) a teoria do desenvolvimento vygotskyana parte da concepção de que todo organismo é ativo e estabelece contínua interação entre as condições sociais, que são mutáveis, e a base biológica do comportamento humano.

A teoria histórico-cultural ou sociocultural do psiquismo humano de Vygotsky, também conhecida como abordagem sócio interacionista, toma como ponto de partida as funções psicológicas dos indivíduos, as quais classificou de elementares e superiores, para explicar o objeto de estudo da sua psicologia: a consciência. (LUCCI, 2015, p. 7). 
Assim, o psiquismo humano se organiza entorno das categorias atividade e consciência sob a ótica da dialética, da afetividade e identidade. Dessa forma, a noção de historicidade considera a produção humana histórica e sua relação com os diferentes grupos sociais, definidos pela realidade local e material do sujeito.

Para Martinez (2003), o indivíduo, em interação constante com seu contexto social (familiar, comunitário), ou seja, o lugar onde vive, é o eixo da produção e utilização do conhecimento psicológico numa prática comprometida com o desenvolvimento, a justiça e a equidade social. Desse modo, analisar como o sujeito vive e se organiza são condições essenciais para compreender suas particularidades e personalidades. Nesse contexto, os usuários da Assistência Social devem ter suas necessidades respeitadas, atendidas e superadas. Para se compreender a complexidade humana é preciso atentar para a individualidade do sujeito considerando-a na coletividade representada pela sociedade.

\section{Considerações Finais}

Apesar de, por muito tempo, ter sido utilizada uma ótica assistencialista dentro da Assistência Social no Brasil, reflexo da herança deixada pela colonização do país e pela forma de organização do Estado desde seu princípio, percebe-se uma tentativa de eliminar esse rótulo das práticas assistenciais e transformá-la em direito de todos através de leis e políticas públicas. Vimos aqui à importância do CRAS como promotor da proteção social básica, que é essencial para a sobrevivência digna das famílias que acessam o serviço e, principalmente, para trazer as pessoas em situação de vulnerabilidade até o local para que possam ser auxiliadas dentro de suas necessidades.

Entretanto, nota-se que o ideal buscado pelas normatizações está longe de ser alcançado, seja pela interferência ainda de interesses privados, seja pela negligência do poder público à área ou pela falta de recursos investidos nesse campo, tendo em vista que ele não traz os benefícios políticos que outras esferas, como a saúde, por exemplo, são capazes de proporcionar. Contudo, não se deve achar que a responsabilidade pela prestação de serviço caiba somente ao CRAS, ou mesmo à Assistência Social. Entende-se que o sucesso do trabalho na efetivação dos direitos fundamentais dos cidadãos, neste caso especificamente os direitos 
referentes à Assistência Social, depende de toda a rede de proteção social e de serviços públicos oferecidos.

Neste sentido, surge o trabalho da Psicologia em consonância com a Proteção Social Básica, em todas suas redes de atendimento. Fortalecer os serviços de Assistência dentro de um viés técnico e contando com a interdisciplinaridade na construção de Políticas Públicas eficientes e universais, onde a psicologia exerce um papel fundamental na tentativa de encontrar potencialidades nos indivíduos que possibilitem tomar as rédeas da própria vida, se mostra fundamental para assegurar a cidadania dessas pessoas e possibilitar outra condição de vida a essas famílias com uma extensa história de invisibilidade, negligência e esquecimento. Assim, compreende-se que o psicólogo na Assistência Social já é figura indispensável para o sucesso das instituições de atendimento, já que possui formação adequada para estabelecer vínculos, identificar problemas e intervir mostrando soluções e ajudando o ser humano na resolução de seus problemas internos e consequentemente, colaborando para suas relações extrínsecas também.

\section{Referências}

BRASIL. Ministério do Desenvolvimento Social e Combate à Fome, Secretaria Nacional de Assistência Social - SNAS. Caderno de Orientações: Serviço de Proteção e Atendimento Integral à Família e Serviço de Convivência e Fortalecimento de Vínculos. Brasília: MDS, 2016.

BRASIL. Centro de Referência Técnica em Psicologia e Políticas Públicas (CREPOP). Referência técnica para atuação do(a) psicólogo(a) no CRAS/SUAS. Brasília: CFP, 2007.

BRASIL. Ministério do Desenvolvimento Social e Combate à Fome. Orientações Técnicas. Centro de Referência de Assistência Social - CRAS. Brasília: MDS, 2009b, 72 p.

CRUS, José Ferreira. O sistema Único de Assistência Social - SUAS. In Cadernos deAssistência Social: trabalhador. Belo Horizonte: NUPASS, 2006.

FILHO, I. A. V. Psicologia Escolar e Psicologia Social-Comunitária: diálogos para a construção de uma perspectiva crítica de atuação do psicólogo na escola. Tese de doutorado apresentada ao programa de estudos pós-graduandos em Educação: Psicologia da Educação. SP: PUC, 2005

JACÓ-VILELA, A.M., and SATO, L., orgs. Diálogos em psicologia social [online]. Rio de Janeiro: Centro Edelstein de Pesquisas Sociais, 2012. 482 p. ISBN: 978-85-7982-060-1. 
LUCCI, Marcos Antônio. A proposta de Vigotski: a psicologia sócio-histórica. Disponível em: http://www.ugr.es/local//recfpro/Rev102COL2port.pdf. Acesso em 25 de Nov de 2015.

LANE, S. T. M.; CODO, W. Psicologia social: o homem em movimento. São Paulo: Brasiliense, 2001.

LEI ORGÂNICA DA ASSISTÊNCIA SOCIAL (LOAS), Lei no 8.742 , de 7 de dezembro de 1993, publicada no DOU de 8 de dezembro de 1993. Dispõe sobre a organização da Assistência Social e dá outras providências.

MARTINEZ, A. M. Psicologia e compromisso social: desafios para a formação do psicólogo. In: BOCK, A. M. B. (Org). Psicologia e compromisso social. São Paulo: Cortez, 2003.

MELMAN, J. Família e doença mental: repensando a relação entre profissionais de saúde e familiares. São Paulo: Escrituras, 2001. (Coleção Ensaios Tranversais).

PEREIRA, Maria Ângela Rocha. A Política de Assistência Social. In Cadernos de Assistência Social: trabalhador. Belo Horizonte: NUPASS, 2006.

PIVETA, Ruth Tainá Aparecida; MANSANO, Sonia Regina Vargas. O fazer como potência: atuação da psicologia no sistema único de assistência social. Revista de Psicologia da UNESP 13(2), 2014.

SUAS. Sistema Único de Assistência Social. Programas Sociais - Proteção Social Especial.Disponível em: http://www.mds.gov.br/programas/rede-suas/protecao-socialespecial .Acesso em 15 fev. 2018.

VIGOTSKI, L. S. História deldasarrolo de lãs funcione psíquicas superiores. Em: Obras escolhidas. V. 3.Madrid: Visor Distribuciones, 1995.

WACHHOLZ, Thais; PANCERI, Regina. A atuação do psicólogo no município de Araranguá, na interface com a rede de proteção social para populações em situação de vulnerabilidade. Santa Catarina: UNISUL, 2015.

Como citar este artigo (Formato ABNT):

SILVA, Byanca E. D.; MOREIRA, Henry W.D.; OLIVEIRA, Andreia B de; SILVA, Maria Auxiliadora L.; PIANCÓ, Ana Roberta D. A Atuação da Psicologia na Proteção Social Básica. Id on Line Rev.Mult. Psic., 2018, vol.12, n.40, p.199-213. ISSN: 1981-1179.

Recebido: $12 / 03 / 2018$

Aceito 14/03/2018 